\begin{tabular}{l} 
Sharif University of Technology \\
Scientia Iranica \\
SCIENTIA \\
IRAN \\
Thansactions A: Civil Engineering \\
\hline
\end{tabular}

\title{
An integrated method for sustainable performance-based optimal seismic design of RC frames with non-prismatic beams
}

\author{
A. Kaveh ${ }^{\mathrm{a}, *}$, L. Mottaghi ${ }^{\mathrm{b}}$, and R.A. Izadifard ${ }^{\mathrm{b}}$ \\ a. School of Civil Engineering, Iran University of Science and Technology, Tehran, Iran. \\ b. Department of Civil Engineering, Imam Khomeini International University, Qazvin, Iran. \\ Received 30 May 2021; received in revised form 6 June 2021; accepted 5 July 2021
}

KEYWORDS
Performance-based
seismic design;
Optimal cost;
Optimal $\mathrm{CO}_{2}$
emissions;
Prismatic beams;
Non-prismatic beams;
Metaheuristic
algorithms.

KEYWORDS seismic design; Optimal cost; Optimal $\mathrm{CO}_{2}$ emissions; Non-prismatic beams; algorithms.

\begin{abstract}
In the performance-based optimal seismic design, one attempts to obtain structural design variables to meet the minimum objective function satisfying the strengthbased and performance-based constraints. A limited number of studies have been conducted on the performance-based optimal seismic design of Reinforced Concrete (RC) frames. On the other hand, due to the significance of environmental impacts, further study on the design of $\mathrm{RC}$ buildings aiming at reducing $\mathrm{CO}_{2}$ emissions is required. In this study, a computational procedure is developed for performance-based optimal seismic design of $\mathrm{RC}$ frames with prismatic beams and frames with non-prismatic beams. The objective functions consist of minimizing the cost and $\mathrm{CO}_{2}$ emissions. Nonlinear pushover analysis was performed to analyze the frames. The described procedure was then applied to a fourstory RC frame, and the relationship between optimal cost and optimal $\mathrm{CO}_{2}$ emissions was investigated in the case of frames with prismatic beams and those with non-prismatic beams.
\end{abstract}

(C) 2021 Sharif University of Technology. All rights reserved.

\section{Introduction}

Performance-Based Seismic Design (PBSD) is a methodology for designing structures and has been frequently considered by earthquake engineers. It also has been introduced by various guidelines to rehabilitate existing buildings as well as designing new ones. The purpose of PBSD is to increase the safety of the structure against natural hazards and to design a structure with predictable performance. Based on the importance of the structure and its performance after an earthquake, the codes classify possible damages and

\footnotetext{
*. Corresponding author. Tel.: +982144429493;

Fax: +9821 7r7240398

E-mail address: alikaveh@iust.ac.ir (A. Kaveh)
}

determine the level of performance. In accordance with FEMA-273 [1], Immediate Occupancy (IO), Life Safety (LS), and Collapse Prevention (CP) are considered as performance levels. Pushover analysis is a very popular technique for nonlinear analysis of structures and seismic demand assessment of structures in PBSD.

In traditional methods (trial and error) for designing the structures, the required analysis is repeated until achieving a reasonable design and the quality of the design produced by traditional methods depends on the engineer's experience and ability. The final design obtained by this method is not sufficient to meet both economic and safety criteria simultaneously. Given this, studies have been carried out using optimization methods to solve problems. In these methods, the objective functions, constraints, type of structural analysis, and optimization process may be different. In a number of studies on the performance-based 
optimal seismic design, the objective function was to minimize the construction cost [2-7]. However, the main objective of some other studies was to minimize the total life cycle costs [8-11]. The total life cycle costs come from the initial operation cost as well as other costs of maintenance, damage, and repair, which are expressed as functions of their seismic performance level in the probability of failure. Park et al. [12] used a process for multi-objective performance-based optimal seismic design in Reinforced Concrete (RC) buildings with prismatic beams. In their study, the objective functions involve the cost of materials, $\mathrm{CO}_{2}$ emission, and seismic performance.

Nowadays, reduction of greenhouse gas emissions is a major global challenge. To be specific, $\mathrm{CO}_{2}$ emissions account for the largest amount of greenhouse gases, i.e., about $77 \%$ of greenhouse gases since 2004 [13]. The environmental impact of construction industry on greenhouse gas emissions is considerable. Therefore, strategies have been employed to reduce these effects. One strategy is use of optimization techniques during the structural design, where the objective function reduces the amount of carbon dioxide emissions. Reinforced concrete buildings are made of two types of material, i.e., concrete and steel, and they have different amounts of carbon dioxide emissions. Therefore, they have high potential to reduce $\mathrm{CO}_{2}$ emissions in optimization methods. Camp et al. [14] optimally designed RC frames using big bangbig crunch optimization algorithm. In their study, the objective functions were the minimization of the $\mathrm{CO}_{2}$ emissions and costs. In another study, Camp and Assadollahi [15] minimized the cost and $\mathrm{CO}_{2}$ emissions of RC footings. Yepes et al. [16] proposed a methodology for the optimal design of RC cantilever retaining walls using a hybrid multi-start optimization strategic method based on Variable Neighborhood Search Threshold Acceptance Strategy (VNS-MTAR) algorithm to minimize the cost and $\mathrm{CO}_{2}$ emissions. Kaveh et al. [17] investigated the relationship between the optimal cost and optimal carbon dioxide emissions in the design of RC frames with different heights. The optimal solutions for each frame were obtained through three metaheuristic algorithms. Mergos [18] evaluated the effects of factors such as ductility classes, Peak Ground Accelerations (PGAs), and concrete classes on the reduction of $\mathrm{CO}_{2}$ emissions in design of seismicresistant $\mathrm{RC}$ frames. Yeo and Potra [19] developed a methodology to optimally design $\mathrm{RC}$ frames with the objectives of minimizing $\mathrm{CO}_{2}$ emission and economic cost. They investigated a portal RC frame under gravitational and lateral loads. They also stated that depending on the parameters considered in calculations, the design aiming to minimize $\mathrm{CO}_{2}$ emission would reduce it by $5-10 \%$ compared to that of the optimal design aiming to minimize cost. Oh et al. [20] established a relationship among optimal carbon dioxide emissions, optimal cost, and structural parameters of composite columns (concrete-filled steel tube), in which the type of section (circular and rectangular), number of materials, and strength of each material were regarded as design variables.

Furthermore, a number of studies have been conducted to optimally design frames characterized by non-prismatic elements. In non-prismatic beams, the values of width, depth or both of them may vary. An acceptable height for the floors of buildings can be determined using these types of beams. They are mostly used in bridges, industrial structures, amphitheaters, sport arenas, parking, etc. McKinstray et al. [21] optimally designed single-span industrial steel frames with three types of sections, namely rolled, fabricated, and non-prismatic. Kaveh et al. [22] optimally designed three dimensional steel structures with non-prismatic beams and columns. The optimal weights of frames with non-prismatic elements were compared with the optimal design of frames with prismatic elements. Yavari et al. [23] optimized $\mathrm{CO}_{2}$ emissions and cost of concrete slab frame bridges during the design phase, with the slab being considered as non-prismatic. Kaveh et al. [24] presented a methodology for the sustainable design of $\mathrm{RC}$ frames with non-prismatic beams and investigated the relationship between the optimal cost and optimal carbon dioxide emissions while designing these frames.

A review of the literature shows that a limited number of studies have been conducted on the Performance Based Optimal Seismic Design (PBOSD) of reinforced concrete buildings with the objective of minimizing carbon dioxide emissions. In addition, few studies have been conducted to optimally design RC frames using non-prismatic elements. In a previous study, the authors investigated the relationship between the optimal cost and optimal $\mathrm{CO}_{2}$ emission in the case of RC frames with non-prismatic beams [24]. They employed equivalent linear static analysis to determine the demand for elements and control the strength-based constraints for structures, where the nonlinear behavior of the structures and performancebased constraints were not taken into account.

In this study, RC frames with prismatic beams and $\mathrm{RC}$ frames with non-prismatic beams were optimized with the objective of minimizing $\mathrm{CO}_{2}$ emission and construction cost. The nonlinear static (pushover) analysis was carried out using the structural optimization strategy to optimally design frames at the performance levels. The relationship between the optimal cost and optimal $\mathrm{CO}_{2}$ emissions of frames at performance levels was also investigated. Five metaheuristic algorithms consisting of the Particle Swarm Optimization (PSO), Colliding Bodies Optimization (CBO), Enhanced Colliding Bodies Opti- 
mization (ECBO), Vibrating Particles System (VPS), and Enhanced Vibrating Particles System (EVPS) were used in the optimal design of the frames with prismatic beams at the IO performance level. The most competent algorithm was then selected and used to solve the remaining problems.

\section{Formulation of optimal design}

2.1. Performance-based optimal seismic design In the performance-based optimal design, the problem formulation can be obtained based on Eq. (1). Here, $f(x)$ is the objective function, $g_{j}^{S B D}$ the strength-based constrains, $g_{j}^{P B D}$ the performance-based constraints, and $x$ the design variables. First, equivalent static analysis was carried out for structures, and strengthbased constraints based on ACI 318-08 [25] code were checked. Then, the performance-based constraints that were related to the maximum inter-story drift were checked under nonlinear static analysis at three performance levels based on FEMA code [1]:

$$
\begin{aligned}
& \min f(x) \\
& g_{j}^{S B D}, \quad j=1, \ldots, m \\
& g_{j}^{P B D}, \quad j=1, \ldots, k \\
& x^{L} \leq x \leq x^{U} .
\end{aligned}
$$

According to the ACI 318-08 code, the following load combinations (Eq. (2)) were used in the equivalent static analysis. Here, $D$ is the dead load, $L$ the live load, and $E$ the lateral equivalent static loads:

$$
\begin{array}{cc}
1.2 D+1.6 L \\
Q_{G}^{S B D}: & 1.2 D+L \pm 1.4 E, \\
& 0.9 D \pm 1.4 E .
\end{array}
$$

In pushover analysis, the lateral load should be incrementally applied to the building while the gravity load is constantly applied. In this study, the load combination (Eq. (3)) and lateral load with the pattern based on the first mode shape are used in pushover analysis:

$$
Q_{G}^{P B D}=1.1(D+L) .
$$

In nonlinear static analysis, it is assumed that the structure response is associated with an equivalent single degree of freedom system. The model of structures is pushed by the lateral load until the displacement of the roof reaches the target displacement or mathematical instability occurs. Based on FEMA-356 [26], the target displacement is calculated as follows:

$$
\delta t=C_{0} C_{1} C_{2} C_{3} S_{a} \frac{T^{2}}{4 \pi^{2}} g,
$$

where $C_{0}$ is the modification factor for relating the spectral displacement of a single degree of freedom to the roof of multi degrees of freedom. In addition, $C_{1}$ is the modification factor for converting the calculated displacements from the linear elastic response to the expected maximum inelastic displacements; $C_{2}$ is the modification factor which represents the effect of hysteresis shape on the maximum displacement response. The value of this coefficient is determined based on the structural performance level, type of frame, and period of the structure. Moreover, $C_{3}$ is the modification factor representing the increase in displacement due to the dynamic effects of P-Delta. Finally, $S_{a}$ is the spectral response acceleration versus structural period domain calculated at three performance levels, as shown in the following:

$$
\begin{array}{ll}
\left(\frac{S_{X S}^{i}}{B_{S}}\right)\left(0.4+3 \frac{T}{T_{0}}\right) & \text { for } \quad 0<T<0.2 T_{0}^{i}, \\
S_{a}^{i}=\frac{S_{X S}^{i}}{B_{S}} & \text { for } 0.2 T_{0}^{i}<T<T_{0}^{i} \\
i=I O, L S, C P, & \\
\frac{S_{X 1}^{i}}{B_{1} T} & \text { for } T>T_{0}^{i},
\end{array}
$$

where $T$ is the elastic fundamental period of the structure obtained from the modal analysis of the structure and $i$ represents three performance levels of $\mathrm{IO}, \mathrm{LS}$, and CP.

$T_{0}$ is given by Eq. (6), and $B_{S}$ and $B_{1}$ in accordance FEMA-273 are assumed to be equal to 1 .

$$
\begin{aligned}
& T_{0}^{i}=\left(S_{X 1}^{i} / B_{S}\right) /\left(S_{X S}^{i} / B_{1}\right), \\
& S_{X 1}^{i}=F_{v}^{i} S_{1}^{i} \\
& S_{X S}^{i}=F_{a}^{i} S_{S}^{i},
\end{aligned}
$$

where $F_{a}^{i}$ and $F_{v}^{i}$ are the site coefficients that are determined based on the site class and the values for response acceleration parameters $S_{S}^{i}$ and $S_{1}^{i}$. Table 1 [27] lists the parameters for site class $D$.

The procedure for automatic performance-based optimal seismic design through the selected algorithms is presented in Figure 1.

2.2. Design variables and database for sections In this study, 11 variables for beams and 4 variables for columns were taken into account. Figure 2 shows the variables for non-prismatic beams. These variables include the dimensions of the cross-sections of column elements (depth and width), diameter and number of 
Table 1. Performance-level site parameters for site class of $D$.

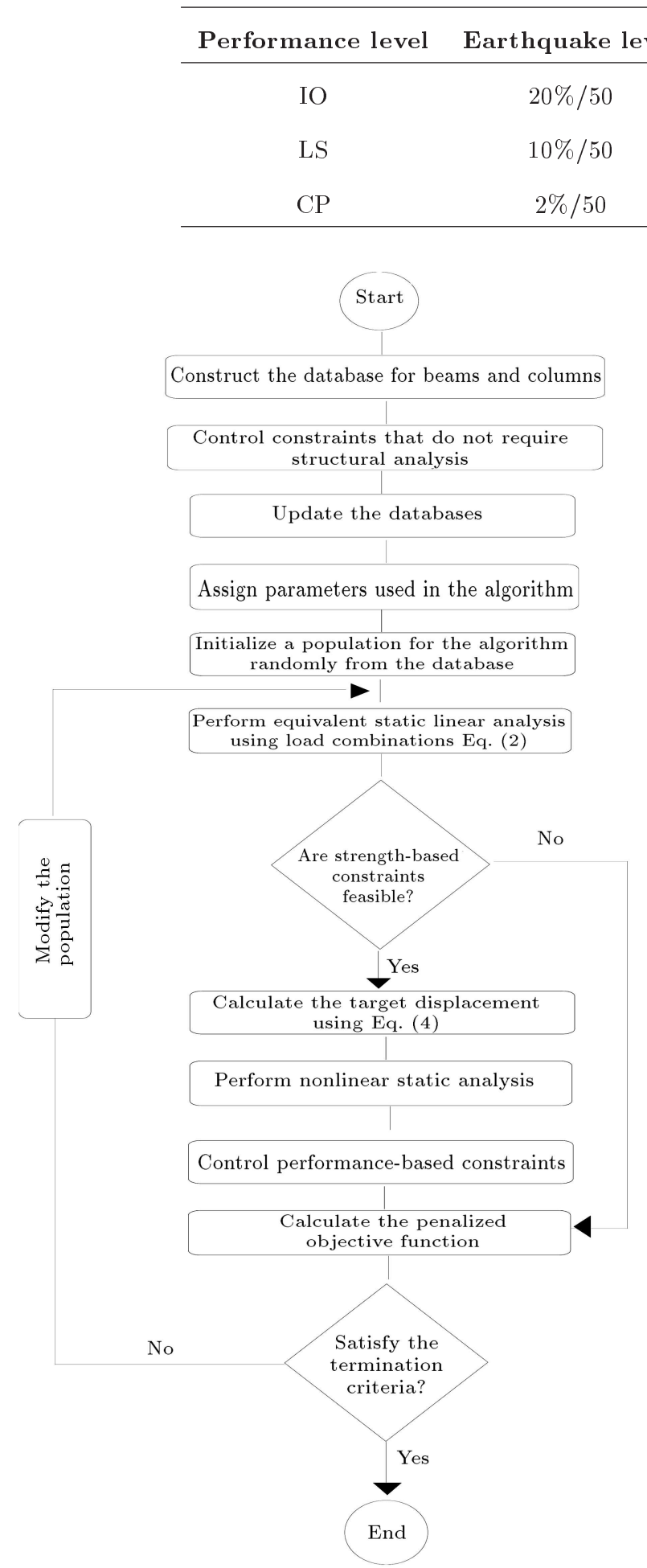

Figure 1. Flowchart of the optimization by the selected algorithms.

longitudinal bars of the columns, depth of the crosssection of beams in prismatic zone $\left(h_{2}\right)$, depth of the cross-section of beams in non-prismatic zone $\left(h_{1}\right)$, diameter and number of longitudinal bars in prismatic section of beams $\left(A s_{2}\right)$ (at the top and bottom of

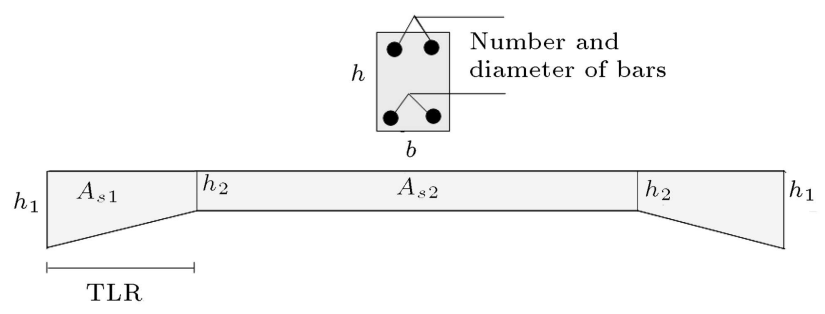

Figure 2. Variables and shape of a non-prismatic beam.

sections), diameter and number of longitudinal bars in the non-prismatic section of beams $\left(A s_{1}\right)$ (at the top and bottom of sections), and length of tapered section that is defined as the percentage of the length of the beam (Tapered Length Ratio (TLR)). The width of cross-section for beams is assumed to be constant. The search space parameters for beams and columns are shown in Table 2.

In order to formulate the variables in the discrete form and reduce the constraint to solve the problem, two databases were created for beams and columns. In these databases, those constraints that do not require structural analysis, such as the percentage of permissible bars, depth-to-width ratio, etc., can be controlled based on the ACI 318-08 code and removed from the database.

\section{Database for beam sections}

In the formulation of database for beams, the width, depth, cross-section area, moment of inertia, number and diameter of bars, bending capacity, and cost or amount of $\mathrm{CO}_{2}$ emission per unit length of the beams are given. In the cross-sections of beams, the depth-towidth ratio varies between 1 and 3 .

The moment-resisting capacity of a beam section is defined by Eq. (9):

$$
M_{n}=A_{s} f_{y}\left(d-\frac{a}{2}\right)
$$

where $A_{s}$ is the total area of tensile reinforcing bars, $f_{y}$ the yield strength of bars, $d$ the distance of the compressive edge of the section to the center of the tensile bars, and $a$ the depth of the equivalent rectangular stress block which is defined as follows:

$$
a=\frac{A_{s} f_{y}}{0.85 f_{c}^{\prime} b},
$$


Table 2. Search space parameters.

\begin{tabular}{|c|c|c|c|c|c|c|}
\hline & & Width (mm) & Depth (mm) & Number of bars & Bar size & TLR \% \\
\hline \multirow{3}{*}{ Column } & Min & 250 & 250 & 4 & 3 & \\
\hline & $\operatorname{Max}$ & 1200 & 1200 & 12 & 11 & \\
\hline & Increment & 50 & 50 & 2 & 1 & \\
\hline \multirow{3}{*}{ Beam } & Min & 350 & 350 & 2 & 3 & 10 \\
\hline & $\operatorname{Max}$ & 350 & 1050 & 5 & 11 & 25 \\
\hline & Increment & & 50 & 1 & 1 & 5 \\
\hline
\end{tabular}

where $f_{c}^{\prime}$ is the compressive strength of the concrete and $b$ the width of the cross-sections.

\section{Database for column sections}

In the formulation of database for column sections, width, depth, area of cross-section, moment of inertia, number and diameter of bars, cost or the amount of $\mathrm{CO}_{2}$ emission per unit length of the column are also given. Furthermore, as shown in Figure 3, the parameters related to the $P-M$ interaction diagram are measured based on the ACI code and then, they are saved in the database. In the cross-section of the columns, the rebars are distributed along all four faces of sections according to the patterns, as shown in Figure 4.

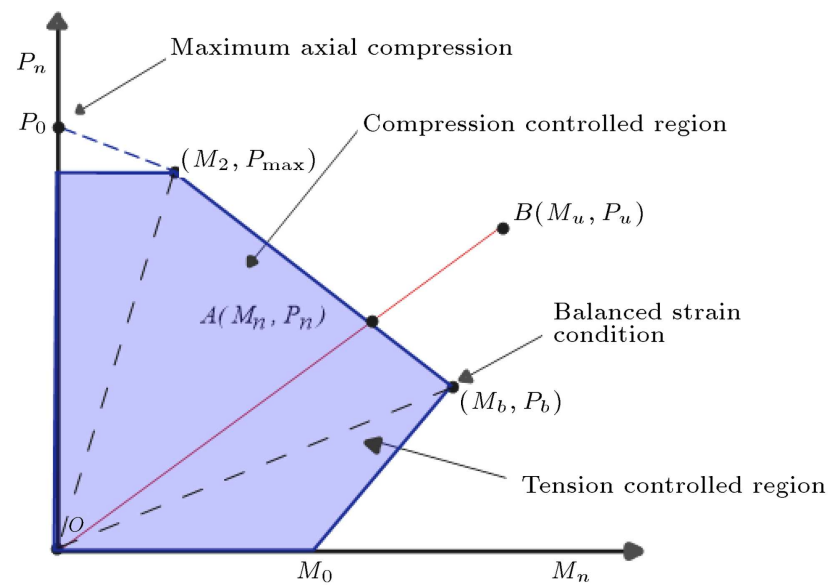

Figure 3. Column load-moment interaction diagram.

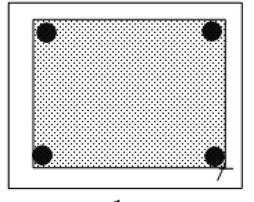

1

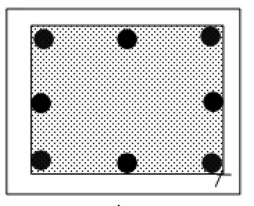

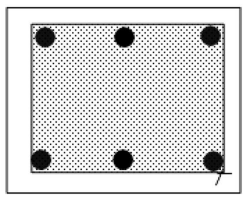

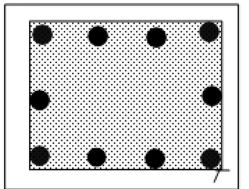

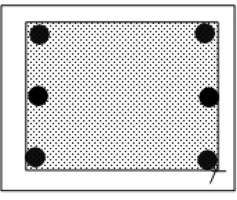

3

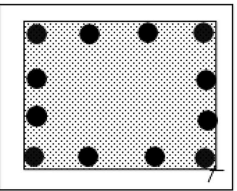

6
Figure 4. Column reinforcement patterns.

\subsection{Objective functions}

In this study, the objective of optimization was to minimize the construction cost and amount of $\mathrm{CO}_{2}$ emissions, as expressed by Eq. (11). Here, $n_{b}$ and $n_{c}$ are the number of beams and columns, respectively; $b_{i}$, $h_{i}, A_{s i}$, and $L_{i}$ are the width, depth of the sections, area of the bars, and length of the beams and columns, respectively; $t_{i}$ is the thickness of the slab that is considered to be $290 \mathrm{~mm}$. In addition, $C_{C}, C_{s}, C_{f}$, and $C_{t}$ are the unit rate of concrete, bars, formwork, and scaffolding, respectively, and their values are listed in Table 3. The parameter $\gamma_{s}$ is the unit weight of steel calculated as $7849 \mathrm{~kg} / \mathrm{m}^{3}$. In the objective function of $\mathrm{CO}_{2}$ emission, scaffolding is neglected.

$$
\begin{aligned}
f_{K}= & \sum_{i=1}^{n_{b}+n_{c}}\left\{C_{C} b_{i} h_{i}+C_{s} \gamma_{s} A_{s i}\right\} L_{i} \\
& +\sum_{i=1}^{n_{b}}\left\{C_{f}\left(b_{i}+2\left(h_{i}-t_{i}\right)\right)+C_{t} b_{i}\right\} L_{i} \\
& +\sum_{i=1}^{n_{c}}\left\{2 C_{f}\left(b_{i}+h_{i}\right)\right\} L_{i} .
\end{aligned}
$$

\subsection{Design constraints}

According to design codes, strength-based and performance-based constraints should be checked during the design process. Equivalent static analysis was done for structures, and the strength-based constraints were checked based on ACI code; then, the performance-based constraints related to the maximum inter-story drift were controlled through pushover analysis at three performance levels. The variables that do not satisfy these constraints are removed from calculations. One method used for avoiding repetitions of calculations for these variables is the penalty function method. In this method, through incorporation of a penalty value to the objective function based on the extent of violation of the constraints, the problem turns into an unconstrained problem. In Eq. (12), the parameters, $g_{i}, x$, and $n$ are the penalty of the $i$ th constraint, vector of design variables, and number of constraints, respectively. Furthermore, $f_{p}$ is the penalized objective function, and $f$ is the value of the 
Table 3. Unit prices and $\mathrm{CO}_{2}$ emissions [14].

\begin{tabular}{ccccccc}
\hline & & \multicolumn{2}{c}{ Cost $(€)$} & & \multicolumn{2}{c}{$\mathbf{C O}_{\mathbf{2}}(\mathbf{k g})$} \\
\cline { 3 - 4 } Description & Unit & Beam & Column & & Beam & Column \\
\hline Steel B-500 & $\mathrm{kg}$ & 1.3 & 1.3 & & 3.01 & 3.01 \\
Concrete (40 MPa) & $\mathrm{m}^{3}$ & 105.93 & 105.17 & & 143.77 & 143.77 \\
Form work & $\mathrm{m}^{2}$ & 25.05 & 22.75 & & 3.13 & 8.9 \\
Scaffolding & $\mathrm{m}^{2}$ & 38.89 & - & & - & - \\
\hline
\end{tabular}

objective function. In this study, the value of $k$ is considered as 1.5 .

$$
f_{p}(x)=f \times\left(1+\sum_{i=1}^{n} \max \left(0, g_{i}(x)\right)\right)^{k} .
$$

\subsubsection{Strength-based constraints \\ Constraints of the beams}

In order to evaluate the moment capacity of the $\mathrm{RC}$ beams, the penalty function is measured, as shown in Eq. (13). In non-prismatic beams, this constraint is examined in Sections $1-5$ as in Figure 5. Section 3 is where the positive bending moment has the maximum value.

$$
g_{1}=\frac{\left|M_{u}\right|-\phi M_{n}}{\phi M_{n}}
$$

where $M_{u}$ is the ultimate applied bending moment under the applied loading and $\phi$ is the strength reduction factor which is equal to 0.9 . In addition, $M_{n}$ is the moment capacity of the RC beams, as defined in Eq. (9).

According of ACI code, the ratios of minimum and maximum reinforcement of the beam sections are limited. The penalties of these constraints are as follows:

$$
\begin{aligned}
& \rho_{\min }=\frac{\sqrt{f_{c}^{\prime}}}{4 f_{y}} \geq \frac{1.4}{f_{y}}, \quad g_{2}=\rho_{\min }-\rho, \\
& \rho_{\max }=0.85 \beta_{1} \frac{f_{c}^{\prime}}{f_{y}} \frac{600}{600+f_{y}}, \quad g_{3}=\rho-\rho_{\max } .
\end{aligned}
$$

In order to control the deflection of the beams, the following penalty was employed in this study.

$$
h_{\min }=\frac{L}{21}, \quad g_{4}=\frac{h_{\min }-h}{h_{\min }} .
$$

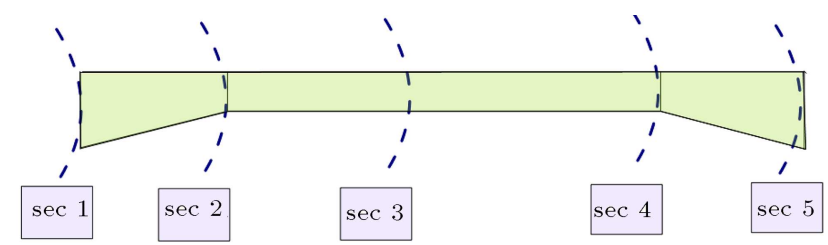

Figure 5. Critical sections along the non-prismatic beams.
In the section of beams, in case the effective depth $(d)$ is lower than the compression-block depth $(a)$, the penalty is defined as follows:

$$
g_{5}=\frac{a-d}{d} .
$$

The minimum distance between the bars should be limited. The penalty of this constraint is defined as:

$$
g_{6}=\frac{s_{\min }-s}{s_{\min }}, \quad s_{\min }=\max \left(d_{b}, 1 \text { inch }\right) .
$$

According to Figure 2, secondary height $\left(h_{2}\right)$ must not be greater than the initial height $\left(h_{1}\right)$; therefore, the penalty can be defined as:

$$
g_{7}=\frac{h_{2}-h_{1}}{h_{2}} .
$$

\section{Constraint of columns}

In case the combination of $\left(M_{u}, P_{u}\right)$ under the applied loads falls inside the interaction $P-M$ diagram, a column section is suitable. The penalty function for the capacity of the columns can be expressed as follows:

$$
g_{8}=\frac{L}{L_{0}}-1
$$

In Figure 3, $l$ is the distance between the origin of the interaction diagram $(\mathrm{O})$ and Point $(\mathrm{B})$ indicating the position of combination $\left(M_{u}, P_{u}\right)$, and $l_{0}$ is the radial distance between the origin of the interaction diagram $(\mathrm{O})$ and Point $(A)$ indicating the intersection point of the vector $l$ with the interaction diagram.

The total area of bars $\left(A_{s}\right)$ in the cross-section of the RC column is limited between $1 \%$ and $8 \%$ of the cross section $\left(A_{g}\right)$. The penalties of the minimum and maximum reinforcement for the columns are expressed as:

$$
\begin{aligned}
& g_{9}=\frac{0.01 \times A_{g}}{A_{S}}-1 \leq 0, \\
& g_{10}=\frac{A_{S}}{0.08 \times A_{g}}-1 \leq 0 .
\end{aligned}
$$

The function penalty defined for the distance between longitudinal bars is:

$$
g_{11}=\frac{s_{\min }-s}{s_{\min }}, \quad s_{\min }=\max \left(1.5 d_{b}, 1.5 \text { inch }\right) .
$$


The dimensions of columns in each story should be smaller than or equal to those of columns on the bottom story; hence, the constraints can be expressed as follows:

$$
\begin{aligned}
& g_{12}=\frac{b_{T}}{b_{B}}-1, \\
& g_{13}=\frac{h_{T}}{h_{B}}-1,
\end{aligned}
$$

where $B$ and $T$ present the bottom column and top column, respectively; and $b$ and $h$ are the width and depth of the column cross-section, respectively.

\subsubsection{Performance based constraint}

Lateral drift is an important indicator for measuring damage in structures that should be controlled in seismic design [28]. Performance-based constraints are expressed as lateral drift at different performance levels, as shown in the following:

$$
\begin{aligned}
& g_{14}=\frac{\theta_{\max }^{I O}}{\theta_{\text {allow }}^{I O}}-1, \\
& g_{15}=\frac{\theta_{\max }^{L S}}{\theta_{\text {allow }}^{L S}}-1, \\
& g_{16}=\frac{\theta_{\max }^{C P}}{\theta_{\text {allow }}^{C P}}-1,
\end{aligned}
$$

where $\theta_{\max }^{I O}, \theta_{\max }^{L S}$, and $\theta_{\max }^{C P}$ are the maximum interstory drift of frame at the performance levels of IO, LS, and CP, respectively. Further, based on FEMA$273, \theta_{\text {allow }}^{I O}, \theta_{\text {allow }}^{L S}$, and $\theta_{\text {allow }}^{C P}$ are allowable drifts that are determined to be $1 \%, 2 \%$, and $4 \%$ for IO, LS, and $\mathrm{CP}$ performance levels, respectively.

\subsection{Structural analysis model}

The finite element software Opensees [29] was employed in this study to model the frames. Linear static and nonlinear static analyses of the structures and determination of the demand of the elements are performed using the mentioned software package. The limitations of the ACI and FEMA codes and optimization algorithm were handled in MATLAB software [30]. While the beams and columns were modeled with the elastic beam column element in the linear static analysis, nonlinear beam column element with distributed plasticity was used to model beams and columns in nonlinear static analysis. Moreover, to model non-prismatic beams upon dividing each non-prismatic element into 12 parts, the step-by-step method was employed. Nonlinear concrete and steel material properties are provided in Table 4. According to this table, the effects of confined and unconfined parts of the fiber section are imposed on the definition of concrete properties. Further, the P-Delta effects were included as geometric transformation. Hence, both material and geometry nonlinearity were taken into account.

\section{Optimization algorithms}

In this section, the algorithms used in this paper are introduced. PSO is a well-known algorithm that has been widely employed in many studies. In addition, ECBO, EVPS, VPS, and CBO algorithms have been recently developed and compared with the previously developed ones, and they were found to be comparatively efficient.

\subsection{Colliding Bodies Optimization (CBO)}

The CBO algorithm [31] is inspired by the laws of momentum and energy of the physics, where the bodies collide with each other and move to the lower cost. Each of Colliding Bodies (CB) is a solution candidate that contains a number of variables. The procedure of the $\mathrm{CBO}$ algorithm can be expressed as:

Step 1: First, the initial position of each $\mathrm{CB}$ is randomly obtained in the search space as follows:

Table 4. The properties of materials.

\begin{tabular}{lccccc}
\hline \multicolumn{5}{c}{ Concrete (uniaxial material concrete01) } \\
\hline Material type & $\boldsymbol{f}_{\mathrm{c}}^{\prime}(\mathrm{MPa})$ & $\varepsilon_{\mathrm{co}_{0}}$ & $\boldsymbol{f}_{\mathrm{cu}}^{\prime}(\mathrm{MPa})$ & $\varepsilon_{\mathrm{cu}}$ \\
\hline Core concrete of beams (confined) & 44 & 0.00296 & 15.3 & 0.0148 \\
Core concrete of columns (confined) & 48 & 0.0032 & 16.8 & 0.048 \\
Cover concrete (unconfined) & 40 & 0.0025 & 14 & 0.0055 \\
\hline
\end{tabular}

Steel (uniaxial material steel01)

\begin{tabular}{lccc} 
Material type & $\boldsymbol{f}_{\boldsymbol{y}}(\mathbf{M P a})$ & $\boldsymbol{E}_{\mathbf{0}}$ & Hardening ratio \\
\hline Reinforcing steel & 500 & $2 \mathrm{e} 5$ & 0.01 \\
\hline
\end{tabular}




$$
x_{i}^{0}=x_{\min }+\operatorname{rand}\left(x_{\max }-x_{\min }\right), \quad i=1,2, \ldots, n,
$$

where $x_{i}^{0}$ is the initial position of the $i$ th $\mathrm{CB} ; x_{\max }$ and $x_{\min }$ are the minimum and maximum allowable values of variables, respectively. The rand parameter is a random value in the range $[0,1]$, and $n$ is the number of CB.

Step 2: In the next step, the mass of each object is determined as follows:

$$
m_{k}=\frac{\frac{1}{f i t(k)}}{\sum_{i=1}^{n} \frac{1}{f i t(i)}}, \quad k=1,2, \ldots, n,
$$

where $f i t(i)$ presents the objective function value for the $i$ th colliding body and $n$ is the number of populations. Arranged in a descending order, the objects are divided into two equal groups of stationary and moving objects. To improve the position of moving objects and move the stationary objects toward a better position, the moving object moves toward a stationary object; hence, collision occurs (Figure 6).

Step 3: The velocity of stationary objects before collision is zero, and the velocity of the moving objects before collision is calculated as follows:

$$
\begin{aligned}
& v_{i}=0, \quad y=1,2, \ldots, \frac{n}{2}, \\
& v_{i}=x_{i-\frac{n}{2}}-x_{i}, \quad i=\frac{n}{2}+1, \ldots, n .
\end{aligned}
$$

Step 4: After the collision of the moving and stationary objects, the velocity of the objects is calculated as follows:

Stationary objects:

$$
v_{i}^{\prime}=\frac{\left(m_{i+\frac{n}{2}}+\varepsilon m_{i+\frac{n}{2}}\right) v_{i+\frac{n}{2}}}{m_{i}+m_{i+\frac{n}{2}}}, \quad i=1,2, \ldots, \frac{n}{2} .
$$

Moving objects:

$$
v_{i}^{\prime}=\frac{\left(m_{i}-\varepsilon m_{i-\frac{n}{2}}\right) v_{i}}{m_{i}+m_{i-\frac{n}{2}}}, \quad i=\frac{n}{2}+1, \ldots, n .
$$

Coefficient of restitution $(\varepsilon)$ is defined as:

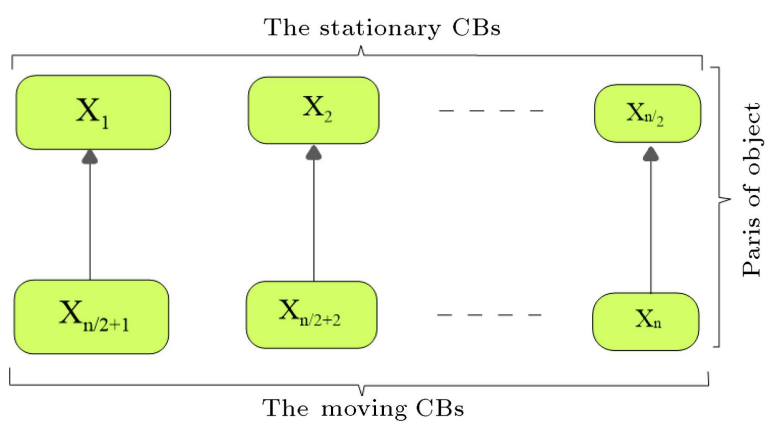

Figure 6. The pairs of objects for collision.

$$
\varepsilon=1-\frac{\text { iter }}{\text { iter }_{\max }} .
$$

Step 5: Through the generated velocities after the collision and their old position, the new positions of the objects for both groups are updated as follows:

The new position of moving object:

$$
x_{i}^{n e w}=x_{i-\frac{n}{2}}+\operatorname{rand}^{o} v_{i}^{\prime}, \quad i=\frac{n}{2}+1, \frac{n}{2}+2, \ldots, n,
$$

where $x_{i}^{n e w}$ is the new position of the $i$ th CBs, $x_{i-\frac{n}{2}}$ is the old position of the $i$ th stationary $\mathrm{CB}$, and rand is a random vector uniformly distribution in the range of $(-1,1)$; further, $v_{i}^{\prime}$ is the velocity of the $i$ th moving $\mathrm{CB}$ after collision. The sign "o" denotes element-byelement multiplication.

The new position of the stationary object can be obtained by:

$$
\begin{aligned}
& x_{i}^{\text {new }}=x_{i-\frac{n}{2}}+\operatorname{rand}^{o} v_{i}^{\prime}, \\
& i=\frac{n}{2}+1, \frac{n}{2}+2, \ldots, n,
\end{aligned}
$$

where $x_{i}^{\text {new }}$ is the new position of the $i$ th CBs, $x_{i-\frac{n}{2}}$ the old position of $i$ th stationary $\mathrm{CB}$ and $v_{i}^{\prime}$ the velocity after the collision of the $i$ th stationary CB.

Step 6: The procedure is repeated from Step 2 until a terminating criterion is accepted.

\subsection{Enhanced Colliding Bodies Optimization ( $E C B O)$}

The performance of the CBO algorithm was modified using two techniques. These techniques were employed to obtain reliable solutions and fast convergence. This algorithm was developed by Kaveh and Ilchi Ghazaan [32] that have been used in many studies, see $[33,34]$. Colliding Memory (CM) was employed to modify the obtained solutions in each step. It stores some of the best CBs in the previous population in each iteration and replaces them with the worst CBs in the current population. Introducing new objects to the population can improve the performance of the algorithm without increasing the computational cost. To improve the exploration capabilities and prevent premature convergence, a component of CBs is randomly regenerated in each iteration. The value for this parameter, which is expressed as Pro, is in the range of $(0,1)$. The steps of this algorithm are as follows:

Step 1: The initial position of all CBs vectors with a number of variables is randomly selected;

Step 2: The mass of each CB is calculated based on Eq. (30);

Step 3: Some of the vectors of the best CBs are stored in $\mathrm{CM}$ and replaced by the worst ones; 
Step 4: The objects are divided into two equal groups of stationary and moving objects based on Figure 6;

Step 5: The velocity of the moving objects before collision is obtained through Eq. (32);

Step 6: The velocity of objects after collision is obtained through Eqs. (33) and (34);

Step 7: The new position of objects is obtained using Eqs. (36) and (37);

Step 8: The Pro parameter is compared with the random number $r n i(i=1,2, \ldots, n)$; If Pro $>$ $r n i$, a $\mathrm{CB}$ is randomly selected from both moving and stationary groups and one related component regenerate;

Step 9: Return to Step 2 until terminating criterion is satisfied.

\subsection{Vibrating Particles System (VPS)}

VPS algorithm was proposed by Kaveh and Ilchi Ghazaan [35]. It is inspired by the free vibration of singledegree-of-freedom systems with viscous damping. It is made up of particles that contain a number of variables. In this algorithm, three parameters with different weights are defined to form the new position: $H B$, the historically best position of the entire population; $G B$, a good particle; and $B P$, a bad particle. With a combination of the current population and historically best position, a balance between diversification and intensification is established and the particles approach equilibrium positions. The procedure of this algorithm is defined as:

Step 1: In this algorithm, the initial position of all particles in the research space is randomly determined.

$$
x_{i}^{j}=x_{\min }+\operatorname{rand}\left(x_{\max }-x_{\min }\right), \quad i=1,2, \ldots, n,
$$

where $x_{i}^{j}$ is the $j$ th variable of the particle $i ; x_{\text {min }}$ and $x_{\max }$ are the minimum and maximum allowable values of the research space. Further, rand is a rand number between $[0,1]$, and $n$ represents the number of particles;

Step 2: The value of the target function is calculated for each particle;

Step 3: For each particle, three balanced positions with different weights are defined, and their positions are updated. The positions are $H B$ (the historically best position of the entire population), GP (a good particle), and BP (a bad particle). In order to select good and bad particles, the population must be arranged in an ascending order according to the values of their objective function. Finally, the $G P$ and $B P$ particles are randomly selected from the first and second halves, respectively. The positions are updated by:

$$
\begin{aligned}
x_{i}^{j}= & w_{1} \cdot\left[D \cdot A \cdot \operatorname{rand} 1+H B^{j}\right] \\
& +w_{2} \cdot\left[D \cdot A \cdot \operatorname{rand} 2+G P^{j}\right] \\
& +w_{3} \cdot\left[D \cdot A \cdot \operatorname{rand} 3+B P^{j}\right],
\end{aligned}
$$

where $w_{1}, w_{2}, w_{3}$ are three parameters used for measuring the relative importance of the $H B, G B$, and $B P$, respectively, and $w_{1}+w_{2}+w_{3}=1$. In addition, rand 1 , rand 2 , and rand 3 are random numbers that are uniformly distributed in the range $[0,1]$.

The parameter $D$ is used to evaluate the effect of damping level on vibration, as shown in the following:

$$
D=\left(\frac{i t e r}{i t e r_{\max }}\right)^{-\alpha},
$$

where iter is the current iteration number, iter max $_{\text {max }}$ the total number of iterations for optimization process, and $\alpha$ a constant parameter.

The parameter $A$ is defined as:

$$
\begin{aligned}
A= & {\left[w_{1} \cdot\left(H B^{j}-x_{i}^{j}\right)\right]+\left[w_{2} \cdot\left(G P^{j}-x_{i}^{j}\right)\right] } \\
& +\left[w_{3} \cdot\left(B P^{j}-x_{i}^{j}\right)\right] .
\end{aligned}
$$

The parameter is defined as $p$ within the range of $(0,1)$ to accelerate the convergence of the VPS algorithm. For each particle, $P$ is compared with rand if $P<$ rand; then, $w_{3}=0$ and $w_{2}=1-w_{1}$;

Step 4: The particles move in the search space to find a better result and may violate the side boundary. In order to handle this constraint, a harmony search-based approach is used in this algorithm;

Step 5: Steps 2 to 4 is repeated until the termination criterion is completed.

\subsection{Enhanced Vibrating Particles System ( $E V P S)$}

In order to improve the results of the VPS algorithm through these techniques, the EVPS algorithm was developed so that the convergence speed increased and local optimum was prevented [36]. In this algorithm, the memory parameter acts as $H B$ with the difference that it saves Memory size number of the best historically positions in the entire population. In case the best answer in each iteration is better than the worst value of memory, it is replaced by the worst value in memory. $O H B$ (one of the best historically positions in entire population) is one row of memory that is randomly selected. Eqs. (39) and (41) of the VPS algorithms are replaced by Eqs. (42) and (43) of the EVPS algorithm, where $( \pm 1)$ are used randomly: 


$$
\begin{aligned}
& {\left[\text { D.A.rand } 1+O H B^{j}\right], } \\
& x_{i}^{j}= {\left[\text { D.A.rand } 2+G P^{j}\right], } \\
& {\left[\text { D.A.rand } 3+B P^{j}\right], } \\
&( \pm 1)\left(O H B^{j}-x_{i}^{j}\right), \\
& A=( \pm 1)\left(G P^{j}-x_{i}^{j}\right), \\
&( \pm 1)\left(B P^{j}-x_{i}^{j}\right), \\
& w_{1}+w_{2}+w_{3}=1 .
\end{aligned}
$$

\subsection{Particle Swarm Optimization (PSO)}

PSO is one of the well-known algorithms, and it is widely used in many studies. This algorithm is inspired by swarm intelligence [37]. The positions and velocity of the particles are updated using the following equations to find the global optimum:

$$
\begin{aligned}
V_{i}[t+1]= & W V_{i}[t]+r_{1} c_{1}\left(P_{i}[t]-X_{i}[t]\right) \\
& +r_{2} c_{2}\left(P_{g}[t]-X_{i}[t]\right) \\
X_{i}[t+1]= & X_{i}[t]+V_{i}[t+1] .
\end{aligned}
$$

In these equations, $V$ and $X$ express the velocity and position of each particle, respectively. In addition, $P_{i}$ is the best position for the $i$ th particles, $P_{g}$ the global best position among all particles, and $W$ is Inertia Weight. Further, $c_{1}$ and $c_{2}$ are the personal learning coefficient and global learning coefficient, respectively. Moreover, $r_{1}$ and $r_{2}$ are two random numbers that are uniformly distributed within $(0,1)$.

\section{Numerical examples}

A four-story RC frame with prismatic beams and, again, a frame with non-prismatic beams were taken into account to investigate the objectives of this study. The performance-based optimal seismic design of frames was performed at three performance levels IO, LS, and CP according to FEMA. The objective functions minimize the construction cost and $\mathrm{CO}_{2}$ emissions. The live and dead loads were measured as $24 \mathrm{kN} / \mathrm{m}$ and $36 \mathrm{kN} / \mathrm{m}$, respectively. There are some special approaches to increasing the convergence speed of algorithms [38,39] is used. In order to obtain the best results for this study, a strategy that was introduced by Kazemzadeh Azad [38] is used. In this strategy, to accelerate the convergence speed of the algorithms, the initial population with feasible solutions is replaced by a random population. In this study, the frames were optimized multiple times, and the candidate solution with the lowest penalty was placed as a candidate in the initial population and then, the optimization was performed.

\section{1. $R C$ frame with prismatic beams}

This example is a four-story and two-span frame with prismatic beams. The height of each story is three meters, and the length of each span is 10 meters. The geometry, lateral loading, and grouping of members

\begin{tabular}{|c|c|c|c|c|c|c|}
\hline $\mathrm{CBO}$ & $\begin{array}{l}\text { Cost object } \\
\mathrm{CO}_{2} \text { object }\end{array}$ & $\begin{array}{c}\text { Pop. size } \\
26 \\
22\end{array}$ & & & & \\
\hline \multirow{3}{*}{$\mathrm{ECBO}$} & & Pop. size & CM size & Pro & & \\
\hline & Cost object & 16 & Pop. size/2 & 0.45 & & \\
\hline & $\mathrm{CO}_{2}$ object & 16 & Pop. size/2 & 0.45 & & \\
\hline \multirow{3}{*}{ VPS } & & Pop. size & $\alpha$ & W1 & W2 & $\mathrm{p}$ \\
\hline & Cost object & 18 & 0.05 & 0.3 & 0.4 & 0.2 \\
\hline & $\mathrm{CO}_{2}$ object & 10 & 0.05 & 0.2 & 0.2 & 0.2 \\
\hline \multirow{3}{*}{ EVPS } & & Pop. size & $\alpha$ & W1 & W2 & $p$ \\
\hline & Cost object & 18 & 0.05 & 0.2 & 0.6 & 0.2 \\
\hline & $\mathrm{CO}_{2}$ object & 18 & 0.05 & 0.2 & 0.2 & 0.2 \\
\hline \multirow{3}{*}{ PSO } & & Pop. size & Inertia weight & C1 & $\mathrm{C} 2$ & \\
\hline & Cost object & 26 & 2 & 2 & 2 & \\
\hline & $\mathrm{CO}_{2}$ object & 32 & 2 & 2 & 2 & \\
\hline
\end{tabular}
are shown in Figure 7, including eight column groups and four groups of beams. The procedure described for PBSD was also used to minimize the cost and carbon dioxide emissions at three performance levels, the results of which are presented below.

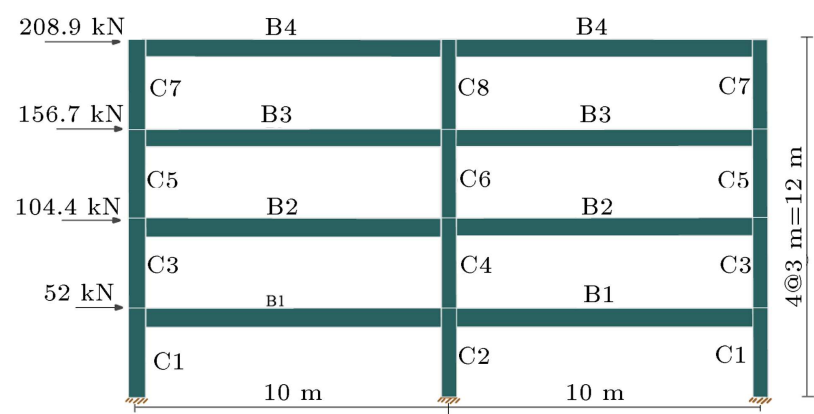

Figure 7. Geometry and grouping of the elements for frame with prismatic beams.

Table 5. Suitable parameters used for each of the algorithms. 


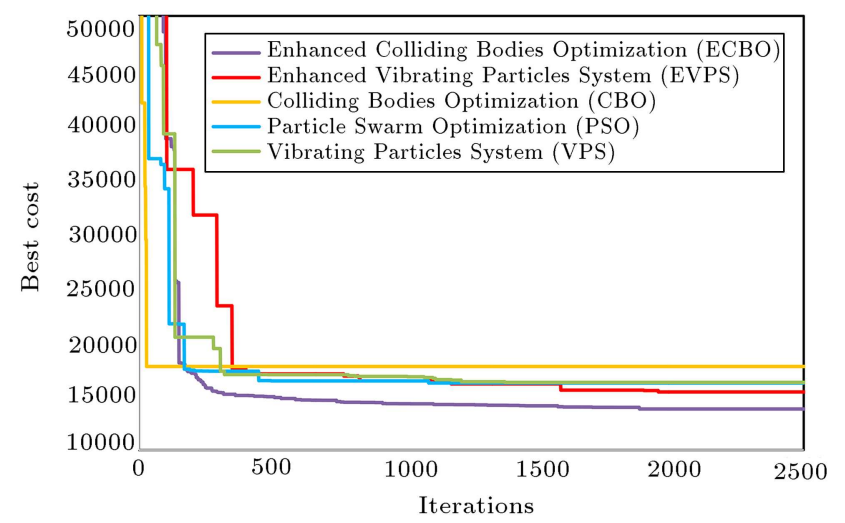

Figure 8. Comparison of the convergence curves of the algorithms for frame with prismatic beams to the lowest cost.

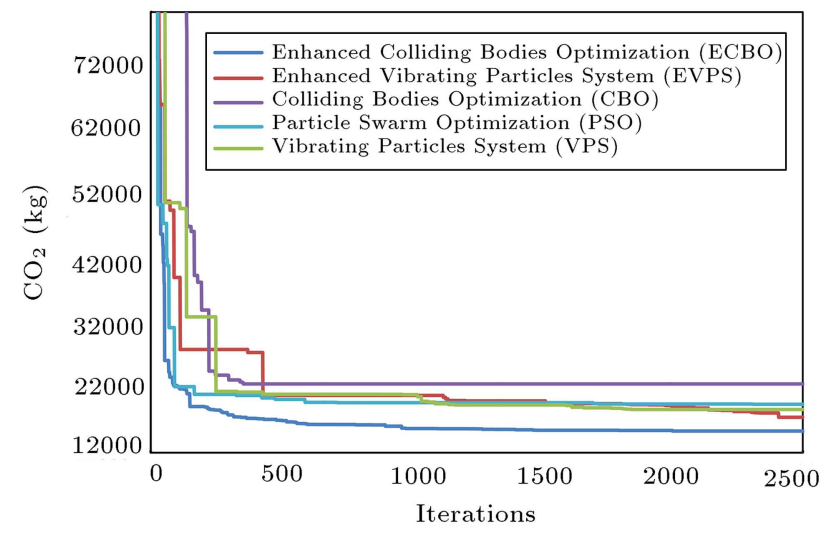

Figure 9. Comparison of the convergence curves of the algorithms for frame with prismatic beams to the lowest $\mathrm{CO}_{2}$ emissions.

At the IO level of performance, five metaheuristic algorithms were used for optimization. The appropriate parameters used for each of the algorithms are listed in Table 5. The convergence curves of the algorithms for the lowest cost and lowest $\mathrm{CO}_{2}$ emissions are compared in Figures 8 and 9, respectively. Table 6 presents the optimal results for all five algorithms. A comparison of the results shows that the ECBO algorithm outperforms the other algorithms in both objective functions; therefore, this algorithm was employed to solve the rest of the problem.

The results of the ECBO algorithm indicate that in the solution with the objective of minimizing cost, the best reported solution is 13770 euro with $15629 \mathrm{~kg}$ of carbon dioxide emissions (Table 7 ). In the solution with the objective of minimizing $\mathrm{CO}_{2}$ emissions, the best reported solution is $15348 \mathrm{~kg}$ with 14082 euro of cost (Table 8). A percentage comparison of results indicates that in the solution based on the objective function of minimizing carbon dioxide emissions, with a $2.2 \%$ increase in cost, the $\mathrm{CO}_{2}$ emissions would be reduced by $1.8 \%$.

The distribution of the inter-story drift ratios obtained from pushover analysis for optimal designs at IO, LS, and CP performance levels with the objectives of minimizing the cost and $\mathrm{CO}_{2}$ emissions is shown in Figures 10 and 11 . Here, the vertical dash line indicates the permissible drift. The drift of stories should not exceed the specified limits.

Figure 12 shows the relationship between the optimal cost and optimal $\mathrm{CO}_{2}$ emissions in the performance-based optimal seismic design at three performance levels, where the objective functions are either $\mathrm{CO}_{2}$ emissions or economic cost. These relationships indicate that in RC frames with prismatic beams, compared to a cost-optimization design, a design based on minimizing $\mathrm{CO}_{2}$ emissions can reduce the $\mathrm{CO}_{2}$ emissions. At the LS and CP performance levels, the optimal design of frames with the objective of minimizing $\mathrm{CO}_{2}$ has more effect on reducing $\mathrm{CO}_{2}$ emissions.

\subsection{The frame with non-prismatic beams}

In this example, the frame of the first example was extended, where the beams are non-prismatic. The lateral loading as well as grouping of beams and columns are shown in Figure 13. Performance-based optimal seismic design was used for this frame to minimize objective functions at three performance levels.

According to the results of the ECBO algorithm at the IO performance level, in the solution with the objective of minimizing the costs, the best reported solution is 12752.19 euro with $15004 \mathrm{~kg}$ of carbon dioxide emissions (Table 9). In the solution with the objective of minimizing $\mathrm{CO}_{2}$ emissions, the best reported solution is $14368 \mathrm{~kg}$ at a cost of 12759 euro (Table 10). A percentage comparison of results reveals that in the solution based on the objective function

Table 6. Comparative results of the algorithms for frame with the prismatic beams at Immediate Occupancy (IO) level.

\begin{tabular}{lcccccc}
\hline & & EVPS & ECBO & VPS & CBO & PSO \\
\hline \multirow{3}{*}{ Cost objective } & Best cost $(€)$ & 15340 & 13770 & 16226 & 17692 & 16160 \\
& $\mathrm{SD}$ & 1717 & 307 & 2780.66 & 551.3 & 2577 \\
& Average $(€)$ & 16278.6 & 14143.7 & 17821.6 & 18815 & 17627.6 \\
& & & & & & \\
$\mathrm{CO}_{2}$ objective & Best $\mathrm{CO}_{2}(\mathrm{~kg})$ & 17745 & 15348 & 18674 & 22621 & 19483 \\
& $\mathrm{SD}$ & 866.2 & 635.9 & 1750.7 & 901.3 & 1144 \\
& Average $(\mathrm{kg})$ & 18830.11 & 16212.2 & 20953.4 & 23940.88 & 20981 \\
\hline
\end{tabular}


Table 7. Optimal results of the cost objective for frame with the prismatic beams at Immediate Occupancy (IO) level.

\begin{tabular}{|c|c|c|c|c|c|}
\hline & \multicolumn{5}{|c|}{ Cost objective } \\
\hline & & $b(\mathbf{m m})$ & $h(\mathbf{m m})$ & $A_{s}$ top & $A_{s}$ bottom \\
\hline \multirow{4}{*}{ Beam group no. } & 1 & 350 & 750 & $3 \# 11$ & $3 \# 8$ \\
\hline & 2 & 350 & 1050 & $4 \# 9$ & $4 \# 6$ \\
\hline & 3 & 350 & 900 & $3 \# 10$ & $2 \# 8$ \\
\hline & 4 & 350 & 950 & $4 \# 8$ & $4 \# 6$ \\
\hline \multirow{8}{*}{ Column group no. } & 1 & 350 & 850 & & $8 \# 8$ \\
\hline & 2 & 350 & 800 & & $6 \# 8$ \\
\hline & 3 & 350 & 800 & & $10 \# 6$ \\
\hline & 4 & 300 & 750 & & $8 \# 6$ \\
\hline & 5 & 300 & 750 & & $8 \# 6$ \\
\hline & 6 & 300 & 700 & & $6 \# 8$ \\
\hline & 7 & 300 & 700 & & $12 \# 7$ \\
\hline & 8 & 250 & 300 & & $4 \# 6$ \\
\hline Average & \multicolumn{5}{|c|}{$14143.7 €$} \\
\hline Std deviation & \multicolumn{5}{|c|}{307} \\
\hline Best solution & \multicolumn{5}{|c|}{ Cost $13770 €\left(\right.$ with $15629 \mathrm{~kg}$ of $\mathrm{CO}_{2}$ emissions $)$} \\
\hline
\end{tabular}

Table 8. Optimal results of $\mathrm{CO}_{2}$ emissions objective for frame with the prismatic beams at Immediate Occupancy (IO) level.

\begin{tabular}{|c|c|c|c|c|c|}
\hline & \multicolumn{5}{|c|}{$\mathrm{CO}_{2}$ objective } \\
\hline & & $b(\mathrm{~mm})$ & $h(\mathrm{~mm})$ & $A_{s}$ top & $A_{s}$ bottom \\
\hline \multirow{4}{*}{ Beam group no. } & 1 & 350 & 950 & $3 \# 10$ & $5 \# 5$ \\
\hline & 2 & 350 & 1050 & $5 \# 8$ & $3 \# 7$ \\
\hline & 3 & 350 & 1050 & $3 \# 10$ & $4 \# 6$ \\
\hline & 4 & 350 & 1000 & $3 \# 9$ & $4 \# 6$ \\
\hline \multirow{8}{*}{ Column group no. } & 1 & 350 & 800 & & $8 \# 7$ \\
\hline & 2 & 350 & 750 & & $10 \# 6$ \\
\hline & 3 & 350 & 800 & & $6 \# 8$ \\
\hline & 4 & 300 & 650 & & $10 \# 5$ \\
\hline & 5 & 300 & 700 & & $8 \# 6$ \\
\hline & 6 & 300 & 650 & & $12 \# 6$ \\
\hline & 7 & 300 & 700 & & $12 \# 7$ \\
\hline & 8 & 250 & 250 & & $12 \# 3$ \\
\hline Average & \multicolumn{5}{|c|}{$16212.2 \mathrm{~kg}$} \\
\hline Std deviation & \multicolumn{5}{|c|}{635.9} \\
\hline Best solution & \multicolumn{5}{|c|}{$\mathrm{CO}_{2} 15347.8 \mathrm{~kg}($ at a cost of $14082 €)$} \\
\hline
\end{tabular}

of minimizing carbon dioxide emissions, with a $0.054 \%$ increase in the cost, $\mathrm{CO}_{2}$ emissions would be reduced by $4.2 \%$.

Figures 14 and 15 show the distribution of the inter-story drift ratios for the frame with non-prismatic beams at IO, LS, and CP performance levels with the objectives of minimizing the cost and $\mathrm{CO}_{2}$ emissions, respectively.

Figure 16 shows the relationship between the optimal cost and optimal $\mathrm{CO}_{2}$ emissions in the 

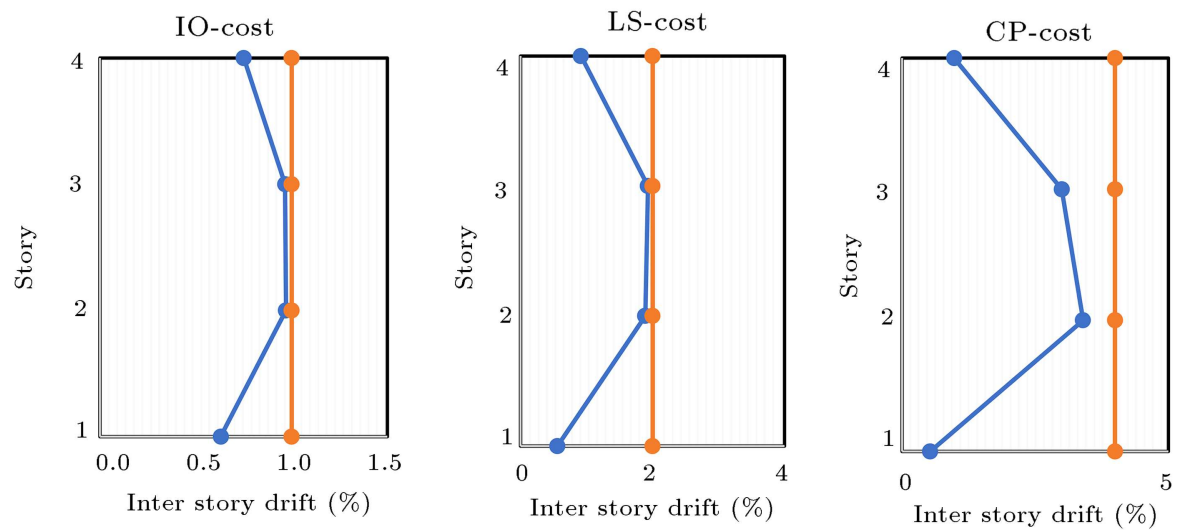

Figure 10. Inter-story drift ratio for the frame with prismatic beams at the three performance levels in the cost objective.
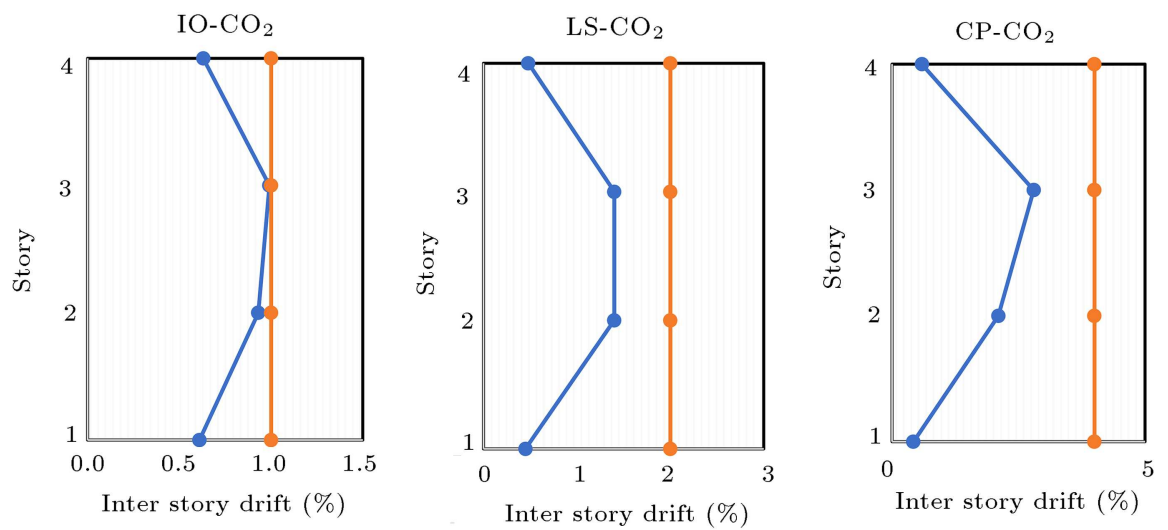

Figure 11. Inter-story drift ratio for the frame with prismatic beams at the three performance levels in the $\mathrm{CO}_{2}$ objective.

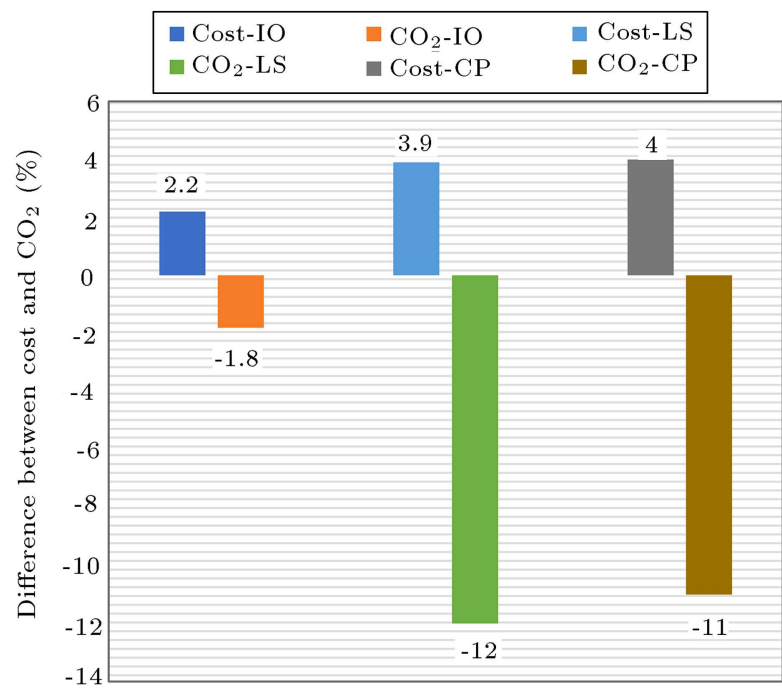

Figure 12. The relationship between optimal cost and optimal $\mathrm{CO}_{2}$ emissions for the frame with prismatic beams.

performance-based optimal seismic design of the frame with non-prismatic beams. At the IO and LS performance levels, the increase in optimal cost is smaller. Therefore, at these levels, design with the objective

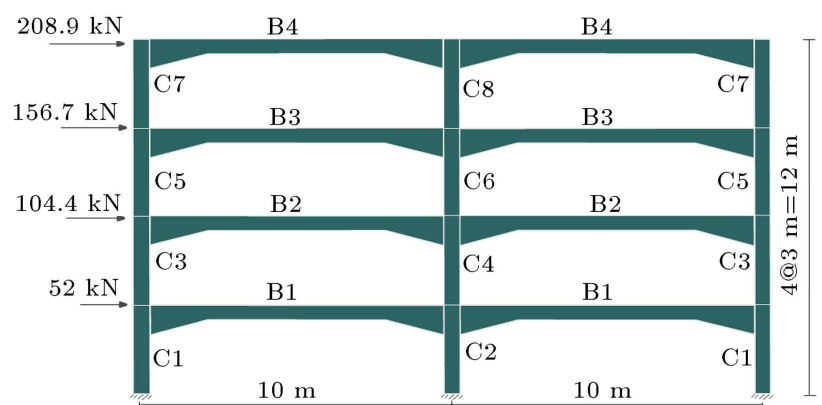

Figure 13. Geometry and grouping of the elements for the frame with non-prismatic beams.

of minimizing $\mathrm{CO}_{2}$ emissions in addition to reduction $\mathrm{CO}_{2}$ have optimal cost.

\section{Concluding remarks}

In this paper, nonlinear static pushover analysis was incorporated to the structural optimization strategy for performance-based optimal seismic design of Reinforced Concrete (RC) frames with prismatic beams and frames with non-prismatic beams. The constraints were controlled in two steps: first, the equivalent static analysis was performed and strength-based constraint 
Table 9. Optimal results of cost objective for frame with the non-prismatic beams at Immediate Occupancy (IO) level.

\begin{tabular}{|c|c|c|c|c|c|c|c|c|c|}
\hline & & $b(\mathbf{m m})$ & $h_{1}(\mathrm{~mm})$ & $h_{2}(\mathrm{~mm})$ & $A_{s 1}$ top & $A_{s 1}$ bottom & $A_{s 2}$ top & $A_{s 2}$ bottom & TLR\% \\
\hline & 1 & 350 & 700 & 450 & $4 \# 10$ & $3 \# 6$ & $5 \# 8$ & $5 \# 7$ & 10 \\
\hline Beam & 2 & 350 & 950 & 700 & $5 \# 8$ & $4 \# 8$ & $2 \# 8$ & $4 \# 6$ & 20 \\
\hline group no. & 3 & 350 & 950 & 750 & $5 \# 8$ & $4 \# 8$ & $3 \# 6$ & $2 \# 8$ & 20 \\
\hline & 4 & 350 & 800 & 800 & $4 \# 10$ & $2 \# 9$ & $4 \# 6$ & $5 \# 6$ & 10 \\
\hline & 1 & 400 & & 000 & & & $6 \# 10$ & & \\
\hline & 2 & 450 & & 100 & & & $10 \# 8$ & & \\
\hline & 3 & 350 & & 50 & & & $6 \# 8$ & & \\
\hline Column & 4 & 400 & & 000 & & & $8 \# 8$ & & \\
\hline group no. & 5 & 350 & & 50 & & & $10 \# 6$ & & \\
\hline & 6 & 350 & & 00 & & & $10 \# 6$ & & \\
\hline & 7 & 300 & & 00 & & & $12 \# 7$ & & \\
\hline & 8 & 250 & & 00 & & & $8 \# 6$ & & \\
\hline Average & \multicolumn{9}{|c|}{$14058 €$} \\
\hline Std deviation & \multicolumn{9}{|c|}{1731.8} \\
\hline Best solution & \multicolumn{9}{|c|}{ Cost $12752.19 €$ (with $15004 \mathrm{~kg}$ of $\mathrm{CO}_{2}$ emissions) } \\
\hline
\end{tabular}

Table 10. Optimal results of $\mathrm{CO}_{2}$ objective for frame with the non-prismatic beams at Immediate Occupancy (IO) level.

\begin{tabular}{|c|c|c|c|c|c|c|c|c|c|}
\hline & & $b(\mathrm{~mm})$ & $h_{1}(\mathrm{~mm})$ & $h_{2}(\mathrm{~mm})$ & $A_{s 1}$ top & $A_{s 1}$ bottom & $A_{s 2}$ top & $A_{s 2}$ bottom & TLR\% \\
\hline \multirow{4}{*}{$\begin{array}{c}\text { Beam } \\
\text { group no. }\end{array}$} & 1 & 350 & 800 & 750 & $4 \# 9$ & $2 \# 9$ & $4 \# 7$ & $4 \# 6$ & 10 \\
\hline & 2 & 350 & 950 & 800 & $4 \# 10$ & $4 \# 6$ & $5 \# 6$ & $4 \# 6$ & 15 \\
\hline & 3 & 350 & 1000 & 650 & $5 \# 8$ & $2 \# 10$ & $4 \# 6$ & $4 \# 6$ & 20 \\
\hline & 4 & 350 & 850 & 800 & $5 \# 8$ & $2 \# 10$ & $5 \# 6$ & $4 \# 6$ & 10 \\
\hline \multirow{8}{*}{$\begin{array}{l}\text { Column } \\
\text { group no. }\end{array}$} & 1 & 450 & \multicolumn{2}{|c|}{1050} & & & $6 \# 10$ & & \\
\hline & 2 & 400 & \multicolumn{2}{|c|}{850} & & & $12 \# 6$ & & \\
\hline & 3 & 350 & \multicolumn{2}{|c|}{800} & & & $10 \# 6$ & & \\
\hline & 4 & 350 & & 00 & & & $10 \# 6$ & & \\
\hline & 5 & 300 & & 50 & & & $10 \# 6$ & & \\
\hline & 6 & 350 & & 00 & & & $10 \# 6$ & & \\
\hline & 7 & 300 & & 00 & & & $8 \# 9$ & & \\
\hline & 8 & 250 & & 00 & & & $6 \# 7$ & & \\
\hline Average & \multicolumn{9}{|c|}{$15030 \mathrm{~kg}$} \\
\hline Std deviation & \multicolumn{9}{|c|}{801.77} \\
\hline Best solution & \multicolumn{9}{|c|}{$\mathrm{CO}_{2} 14368 \mathrm{~kg}($ at a cost of $12759 €)$} \\
\hline
\end{tabular}

were controlled; then, the nonlinear pushover analysis was carried out at three performance levels according to the FEMA code and the maximum inter-story drift was investigated. In order to identify the most competent algorithm for solving the problem, five metaheuris- tic algorithms including Particle Swarm Optimization (PSO), Colliding Bodies Optimization (CBO), Enhanced Colliding Bodies Optimization (ECBO), Vibrating Particles System (VPS), and Enhanced Vibrating Particles System (EVPS) were used to op- 

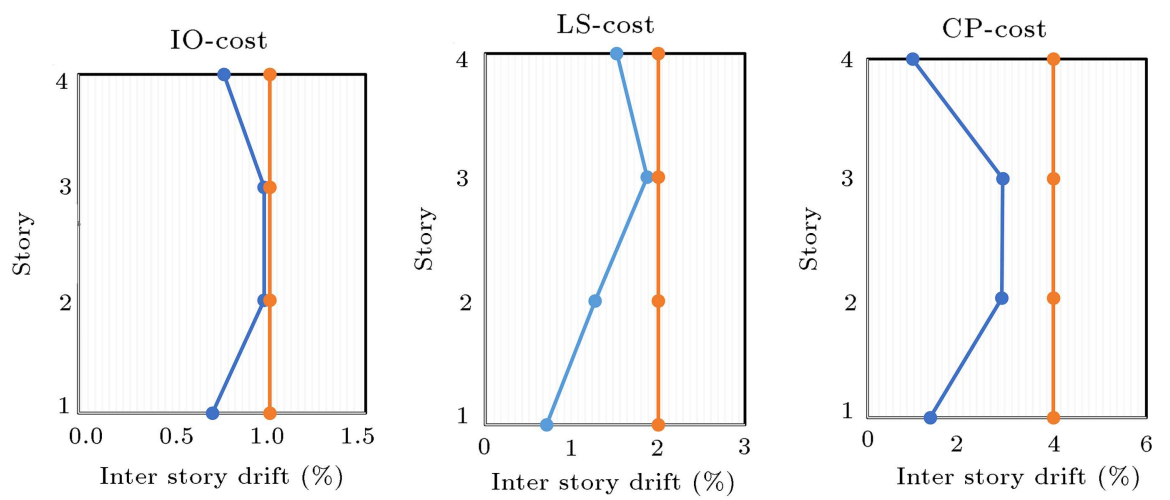

Figure 14. Inter-story drift ratio for the frame with non-prismatic beams at the three performance levels in the cost objective.
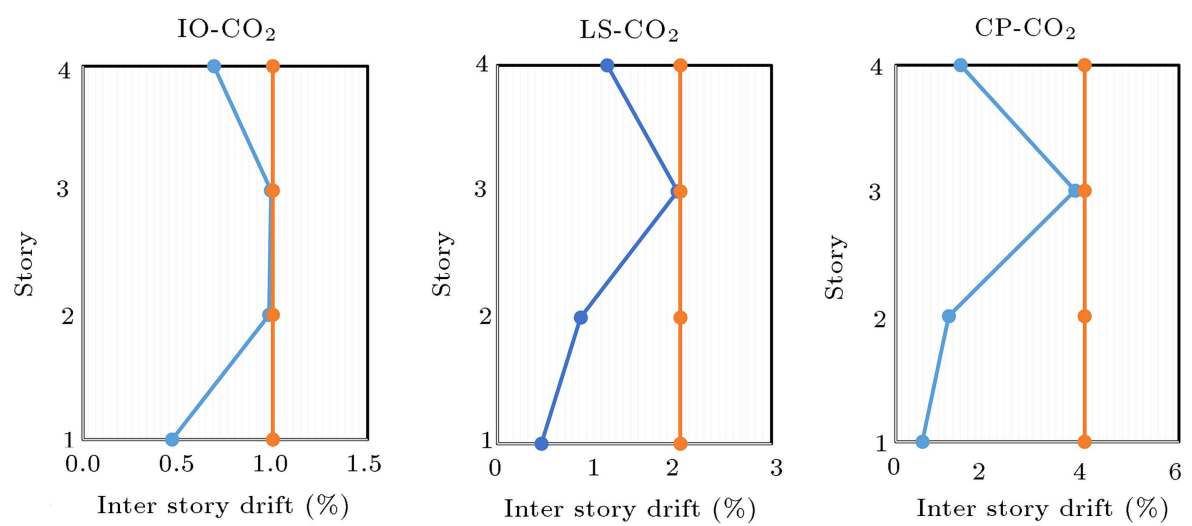

Figure 15. Inter-story drift ratio for the frame with non-prismatic beams at the three performance levels in the $\mathrm{CO}_{2}$ objective.

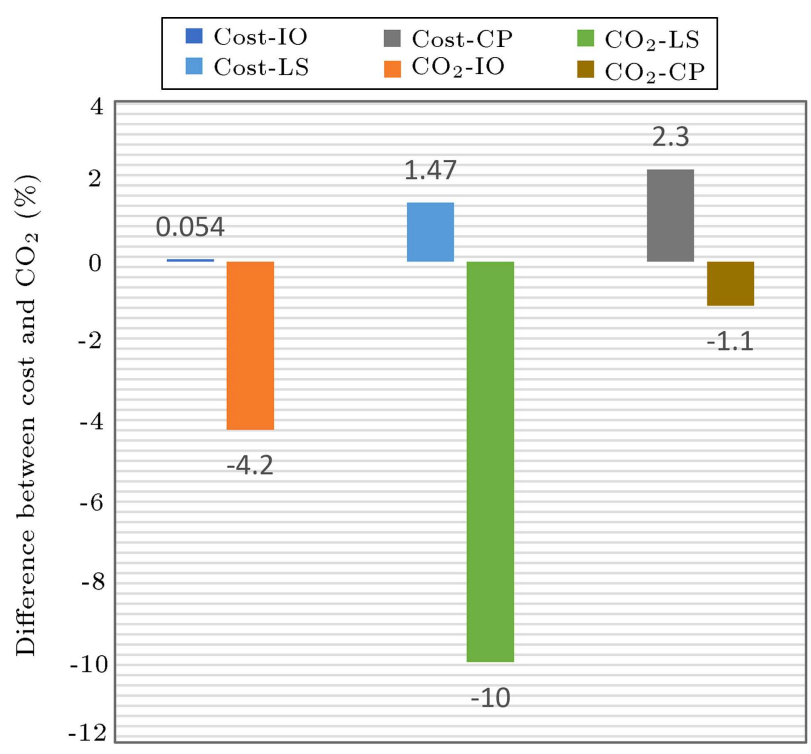

Figure 16. The relationship between optimal cost and optimal $\mathrm{CO} 2$ emissions for frame with non-prismatic beams.

timize the objectives at the Immediate Occupancy (IO) performance level, and the rest of the problems were solved using the selected competent algorithm. Comparison of the performance of the algorithms in the first example demonstrated that ECBO performed better than the other algorithms. The relationships between optimal cost and optimal $\mathrm{CO}_{2}$ emissions in Performance Based Optimal Seismic Design (PBOSD) for three performance levels showed that in the design of $\mathrm{RC}$ frames with the objective of minimizing $\mathrm{CO}_{2}$ emissions, $\mathrm{CO}_{2}$ could be reduced compared to the design with the objective of optimizing cost. In frames with prismatic beams at performance levels, with $2.2 \%$ to $4 \%$ increase in cost, $\mathrm{CO}_{2}$ was reduced by $1.8 \%$ to $12 \%$, and for frames with non-prismatic beams with $0.05 \%$ to $2.3 \%$ increase in cost, the reduced $\mathrm{CO}_{2}$ was $1.1 \%$ to $10 \%$.

\section{References}

1. FEMA-273, "NEHRP guideline for the seismic rehabilitation of buildings", Federal Emergency Management Agency (1997).

2. Zou, X.K. and Chan, C.M. "Optimal seismic performance-based design of reinforced concrete buildings using nonlinear pushover analysis", Eng. Struct., 27(8), pp. 1289-1302 (2005). https://doi.org/10.1016/j.engstruct.2005.04.001

3. Zou, X.K. and Chan, C.M. "An optimal resizing technique for seismic drift design of concrete build- 
ings subjected to response spectrum and time history loadings", Comput. Struct., 83, pp. 1689-1704 (2005). https://doi.org/10.1016/j.compstruc.2004.10.002

4. Zhang, C. and Tian, Y. "Simplified performance-based optimal seismic design of reinforced concrete frame buildings", Eng. Struct., 185, pp. 15-25 (2019). https://doi.org/10.1016/j.engstruct.2019.01.108

5. Papavasileiou, G.S. and Charmpis, D.C. "Seismic design optimization of multi-storey steel-concrete composite buildings", Comput. Struct., 170, pp. 49-61 (2016).

https://doi.org/10.1016/j.compstruc.2016.03.010

6. Gholizadeh, S. "Performance-based optimum seismic design of steel structures by a modified firefly algorithm and a new neural network", Adv. Eng. Softw., 81, pp. 50-65 (2015).

https://doi.org/10.1016/j.advengsoft.2014.11.003

7. Kaveh, A., Farahmand Azar, B., Hadidi, A., Rezazadeh Sorochi, F., and Talatahari, S. "Performancebased seismic design of steel frames using ant colony optimization", J. Constr. Steel Res., 66, pp. 566-574 (2010). https://doi.org/10.1016/j.jcsr.2009.11.006

8. Zou, X.K., Chan, C.M., Li, G., and Wang, Q. "Multiobjective optimization for performance-based design of reinforced concrete frames", J. Struct. Eng., 133(10), pp. $1462-1474$ (2007).

DOI: 10.1061/(ASCE0)733-9445(2007)133:10(1462)

9. Mitropoulou, C.C., Lagaros, N.D., and Papadrakakis, M. "Life-cycle cost assessment of optimally designed reinforced concrete buildings under seismic actions", Reliab. Eng. Syst. Saf., 96(10), pp. 1311-1331 (2011). https://doi.org/10.1016/j.ress.2011.04.002

10. Lagaros, N.D. and Magoula E. "Life-cycle cost assessment of mid-rise and high-rise steel and steel-reinforced concrete composite minimum cost building designs", Struct. Des. Tall Spec. Build, 22(12), pp. 954-974 (2011). https://doi.org/10.1002/tal.752

11. Kaveh, A., Laknejadi, K., and Alinejad, B. "Performance-based multi-objective optimization of large steel structures", Acta Mech., 223(2), pp. 355369 (2012). https://doi.org/10.1007/s00707-011-05641

12. Park, H.S., Hwang, J.W., and Oh, B.K. "Integrated analysis model for assessing $\mathrm{CO}_{2}$ emissions, seismic performance, and costs of buildings through performance-based optimal seismic design with sustainability", Energy Build., 158, pp. 761-775 (2018). https://doi.org/10.1016/j.enbuild.2017.10.070

13. Pachauri, R.K. and Reisinger, A. "United Nations Intergovernmental Panel on Climate Change. Climate change 2007: synthesis report. Contribution of working groups I, II and III to the fourth assessment report of the intergovernmental panel on climate change", Geneva, Switzerland (2007).

14. Camp, C.V. and Huq, F. " $\mathrm{CO}_{2}$ and cost optimization of reinforced concrete frames using a big bang-big crunch algorithm", Eng. Struct. J., 48(2), pp. 363$372(2013)$.

https://doi.org/10.1016/j.engstruct.2012.09.004

15. Camp, C.V. and Assadollahi, A. " $\mathrm{CO}_{2}$ and cost optimization of reinforced concrete footings subjected to uniaxial uplift", J. Build. Eng., 3, pp. 171-183 (2015). https://doi.org/10.1016/j.jobe.2015.07.008

16. Yepes, V., Gonzalez-vidosa, F., Alcala, J., and Villalba, P. " $\mathrm{CO}_{2}$-optimization design of reinforced concrete retaining walls based on a VNS-threshold acceptance strategy", J. Comput. Civ. Eng., 26(3), pp. 378-386 (2012).

http://dx.doi.org/10.1061/(ASCE)CP.19435487.0000140

17. Kaveh, A., Izadifard, R.A., and Mottaghi, L. "Optimal design of planar RC frames considering $\mathrm{CO}_{2}$ emissions using ECBO, EVPS, and PSO metaheuristic algorithms", J. Build. Eng., 28, p. 101014 (2020). https://doi.org/10.1016/j.jobe.2019.101014

18. Mergos, P.E. "Seismic design of reinforced concrete frames for minimum embodied $\mathrm{CO}_{2}$ emissions", Energy Build., 162, pp. 177-186 (2018).

https://doi.org/10.1016/j.enbuild.2017.12.039

19. Yeo, D. and Potra, F.A. "Sustainable design of reinforced concrete structures through $\mathrm{CO}_{2}$ emission optimization", J. Struct. Eng, 141(3), B4014002 (2015).

https://doi.org/10.1061/(ASCE)ST.1943$541 \mathrm{X} .0000888$

20. Oh, B.K., Park, J.S., Choi, S.W., and Park, H.S. "Design model for analysis of relationships among $\mathrm{CO}_{2}$ emissions, cost, and structural parameters in green building construction with composite columns", Energy Build., 118, pp. 301-315 (2016).

https://doi.org/10.1016/j.enbuild.2016.03.015

21. McKinstray, R., Lim, J.B.P., Tanyimboh, T.T., Phan, D.T., and Sha, W. "Comparison of optimal designs of steel portal frames including topological asymmetry considering rolled, fabricated and tapered sections", Eng. Struct., 111, pp. 505-524 (2016). https://dx.doi.org/10.1016/j.engstruct.2015.12.028

22. Kaveh, A., Kabir, M.Z., and Bohlool, M. "Optimum design of three-dimensional steel frames with prismatic and non-prismatic elements", Eng. Comput,, 36, pp. 1011-1027 (2019). https://doi.org/10.1007/s00366-019-00746-9

23. Solat Yavari, M., Du, G., Pacoste, C., and Karoumi, R. "Environmental impact optimization of reinforced concrete slab frame bridges", J. Civ. Eng. Archit., 11(4), pp. 313-324 (2017).

DOI: $10.17265 / 1934-7359 / 2017.04 .001$

24. Kaveh, A., Mottaghi, L., and Izadifard, R.A. "Sustainable design of reinforced concrete frames with nonprismatic beams", Eng. Comput., 123456789 (2020). https://doi.org/10.1007/s00366-020-01045-4 
25. A.C. Institute, Building code requirements for structural concrete and commentary, ACI 318-08 (2008).

26. FEMA-356, Prestandard and Commentary for the Seismic Rehabilitation of Buildings, Federal Emergency Management Agency (2000).

27. Fathali, M.A. and Hoseini Vaez, S.R. "Optimum performance-based design of eccentrically braced frames", Eng. Struct., 202 (2020). https://doi.org/10.1016/j.engstruct.2019.109857

28. Moehle, J.P. and Mahin, S.A., Observations on the Behavior of Reinforced Concrete Buildings During Earthquakes, American Concrete Institute, SP-127 (1991).

29. PEERS and OpenSEES, Open System for Earthquake Engineering Simulation, Pacific Earthquake Engineering Research Centre, University of California, Berkeley (2012).

30. The Language of Technical Computing, MATLAB. Math Works Inc (2016).

31. Kaveh, A. and Mahdavi, V.R. "Colliding bodies optimization: A novel meta-heuristic method", Comput. Struct., 139, pp. 18-27 (2014).

https://doi.org/10.1016/j.compstruc.2014.04.005

32. Kaveh, A. and Ilchi Ghazaan, M. "Enhanced colliding bodies optimization for design problems with continuous and discrete variables", Adv. Eng. Softw., 77, pp. 66-75 (2014).

https://doi.org/10.1016/j.advengsoft.2014.08.003

33. Kaveh, A. and Ghafari, M.H. "Optimum design of castellated beams: Effects of composite action and semi-rigid connections", Sci. Iran., 25(1), pp. 162-173 (2018). https://doi.org/10.24200/sci.2017.4195

34. Kaveh, A. and Sabeti, S. "Optimal design of monopile offshore wind turbine structures using CBO, ECBO, and VPS algorithms", Sci. Iran., 26(3A), pp. 12321248 (2019).

https://doi.org/10.24200/sci.2018.20090

35. Kaveh, A. and Ilchi Ghazaan, M. "A new metaheuristic algorithm: vibrating particles system", Sci. Iran., 24(2), pp. 1-32 (2017).

https://doi.org/10.24200/sci.2017.2417

36. Kaveh, A., Hoseini Vaez, S.R., and Hosseini, P. "Enhanced vibrating particles system algorithm for damage identification of truss structures", Sci. Iran., 26(1A), pp. 246-256 (2019). https://doi.org/10.24200/sci.2017.4265

37. Eberhart, R. and Kennedy, J. "A new optimizer using particle swarm theory", Proc. Sixth Int. Symp. micro
Mach. Hum. Sci., pp. 1942-1948 (1995).

https://doi.org/10.1109/MHS.1995.494215

38. Kazemzadeh Azad, S. "Seeding the initial population with feasible solutions in metaheuristic optimization of steel trusses", Eng. Optim., 50(1), pp. 1-17, no. February (2017).

http://dx.doi.org/10.1080/0305215X.2017.1284833

39. Kazemzadeh Azad, S., Hasançebi, O., and Kazemzadeh Azad, S. "Upper bound strategy for metaheuristic based design optimization of steel frames", Adv. Eng. Softw., 57, pp. 19-32 (2013). https://doi.org/10.1016/j.advengsoft.2012.11.016

\section{Biographies}

Ali Kaveh was born in 1948 in Tabriz, Iran. After graduation from the Department of Civil Engineering in the University of Tabriz in 1969, he continued his studies on Structures at Imperial College of Science and Technology in London University and received his MSc, DIC, and PhD degrees in 1970 and 1974. He then joined the Iran University of Science and Technology. Professor Kaveh is the author of 700 papers published in international journals and has presented 150 papers at national and international conferences. He has authored 23 books in Persian and 10 books in English published by Wiley, Research Studies Press, American Mechanical Society, and Springer.

Lida Mottaghi was born in 1987 in Marand. She obtained her MS degree in Earthquake Engineering from the Khajeh Nasir Toosi University (KNTU), Iran. At present, she is a $\mathrm{PhD}$ student at Imam Khomeini International University (IKIU), Gazvin, Iran. She works on the optimum design of $\mathrm{RC}$ frames via the metaheuristic methods.

Ramezan Ali Izadifard was born in 1966 in Frydonkenar, in the north of Iran. He studied structural engineering at Isfahan University of Technology and Shiraz University and received his BS, MSc, and PhD degrees in 1989, 1992, and 2008, respectively. He is the author of more than 50 papers published in international journals or presented papers at professional conferences. He is currently teaching and researching at Imam Khomeini International University. 